\title{
Produtividade de híbridos de tomate submetidos ao cultivo superadensado
}

\author{
Anderson Fernando Wamser; Siegfried Mueller; Atsuo Suzuki; Walter F Becker; Janaína P dos Santos \\ EPAGRI-EE de Caçador, C. Postal 591, 89500-000 Caçador-SC; afwamser@epagri.sc.gov.br; simueller@epagri.sc.gov.br; suzuki@ \\ epagri.sc.gov.br; wbecker@epagri.sc.gov.br; janapereira@epagri.sc.gov.br
}

\section{RESUMO}

Os tomaticultores da região de Caçador-SC necessitam de resultados experimentais do cultivo superadensado, com os híbridos cultivados nas condições edafoclimáticas da região, para que possam decidir sobre a adoção deste sistema. Desta forma, o objetivo deste trabalho foi avaliar o cultivo superadensado de tomate com híbridos utilizados em Caçador. Dois experimentos foram realizados na Epagri em Caçador, durante as safras 2007/2008 e 2008/2009. Os tratamentos, na safra 2007/2008, consistiram na combinação de dois híbridos (Miramar e T92), dois métodos de tutoramento (vertical e em "V") e dois métodos de condução de plantas (uma haste por planta no espaçamento de $0,15 \mathrm{~m}$ entre plantas e duas hastes por planta no espaçamento de $0,3 \mathrm{~m}$ entre plantas). Na safra 2008/2009, os tratamentos consistiram na combinação de dois híbridos (Paron e Plutão) e dois métodos de condução de plantas superadensado (uma haste por planta no espaçamento entre plantas de $0,15 \mathrm{~m}$ e duas hastes por planta no espaçamento entre plantas de $0,3 \mathrm{~m}$ ). Foi incluído ainda o método de condução e densidade de plantas tradicional (duas hastes por planta no espaçamento entre plantas de $0,6 \mathrm{~m}$ ). O delineamento experimental foi de blocos completos ao acaso, com quatro repetições, no esquema de parcelas sub-subdivididas, na safra 2007/2008, e de parcelas subdivididas, na safra 2008/2009. Os tratamentos possuíam 44.444 hastes/ha, com exceção dos tratamentos com condução tradicional de plantas (22.222 hastes/ha). Foram analisados a produtividade total, comercial e descarte, massa média de frutos comerciais, frutos comerciais $(\%)$ e descarte $(\%)$ em relação ao número total de frutos e severidade de doenças foliares. Os híbridos testados não interferem nas respostas agronômicas ao adensamento de plantas. O sistema superadensado de tomate proporcionou aumento, em média, de $73,2 \%$ na produtividade comercial de frutos, em relação à densidade tradicional de plantas. A produtividade comercial de frutos no tomateiro superadensado tutorado em "V" foi 19,2\% maior que o tomateiro superadensado tutorado verticalmente. A condução de uma haste por planta aumentou $10,4 \%$ a produtividade comercial de frutos em relação à condução de duas hastes por planta no tomateiro superadensado. O tomateiro superadensado proporcionou aumento da severidade foliar de pinta-preta, em relação à densidade tradicional de plantas.

\begin{abstract}
Yield of tomato hybrids subjected to a super density cropping

Farmers of Caçador, Santa Catarina State, Brazil, need experimental results of tomato super density cropping system, since the ecological conditions of this region permit them decide to adopt this system or not. The aim of this work was to evaluate the tomato super density cropping system with hybrids used in Caçador. Two experiments were carried out at Epagri, Experimental Station of Caçador, during the 2007/2008 and 2008/2009 harvest period. The treatments in 2007/2008 were the combination of two hybrids (Miramar and T92), two methods of staking (in vertical and "V") and two methods of training plants (one stem per plant in the spacing of $0.15 \mathrm{~m}$ between plants and two stems per plant in the spacing of $0.3 \mathrm{~m}$ between plants). In 2008/2009, the treatments were the combination of two hybrids (Paron and Plutão) and two super density methods of training plants (one stem per plant in the spacing of $0.15 \mathrm{~m}$ between plants and two stems per plant in the spacing of $0.3 \mathrm{~m}$ between plants) plus the traditional density and method of training plants (two stems per plant in the spacing of $0.6 \mathrm{~m}$ between plants). The experimental design was of randomized complete blocks with four replications in a split-split-plot, in 2007/2008, and a split-plot in the 2008/2009 season. All treatments had 44,444 stems/ha, except for the treatments with traditional methods of training plants (22,222 stems/ha). The variables analyzed were total, marketable and unmarketable yield, average mass of fruits, marketable and unmarketable percentage of fruits in relation to the total number of fruits, and severity of leaf diseases. The tomato hybrids do not interfere in agronomic responses to the super density of plants. The super density of plants increased, on average, $73.2 \%$ the marketable yield, in relation to the traditional density of plants. The marketable yield of the super density of plants in the "V" staking was $19.2 \%$ higher than the super density of plants in the vertically staking. The plant training with one stem per plant increased $10.4 \%$ the marketable yield in relation to the plant training with two stems per plant in the super density of plants. The super density of plants increased the leaf severity of early blight, in relation to the traditional density of plants.
\end{abstract}

Keywords: Lycopersicon esculentum, staking, plant spacing.

Palavras-chave: Lycopersicon esculentum, tutoramento, espaçamento.

\section{(Recebido para publicação em 29 de outubro de 2011; aceito em 16 de fevereiro de 2012) (Received on October 29, 2011; accepted on February 16, 2012)}

$\mathrm{R}$ ecentemente foi divulgado nos meios de comunicação um sistema de cultivo de tomate a campo em alta densidade desenvolvido por técnicos do Espírito Santo, denominado tomateiro superadensado (Oliveira, 2006; Melo, 2007). As principais características deste sistema são o plantio de aproximada- mente 44.000 plantas/ha, conduzindo-se uma haste por planta e mantendo-se cinco a sete cachos por haste, através da desponta. Esta densidade de plantas é obtida com o espaçamento de $0,15 \mathrm{~m}$ entre plantas e 1,5 m entre filas. Além disso, as hastes são tutoradas por fitilhos que são amarrados de forma alternada em dois arames fixados nos moirões, em altura aproximadamente de 2,0 m, dispostos ao longo das filas de plantas e distanciados entre eles em $0,5 \mathrm{~m}$ na respectiva fileira.

A referida forma de tutoramento das plantas confere o formato de "V" ao longo da linha de plantio. Segundo 
os técnicos que desenvolveram este sistema, o tomateiro superadensado, nas condições do Espírito Santo, proporciona o dobro da produtividade do cultivo tradicional, que é de 12.000 plantas/ ha, conduzindo duas hastes por planta. Esses técnicos ainda comentam que há aumento da porcentagem de frutos Extra AA, redução da mão-de-obra, devido à facilidade nos tratos culturais e agilidade na colheita, e diminuição do custo de produção por caixa (Oliveira, 2006; Melo, 2007).

As práticas adotadas na proposta do tomateiro superadensado como o adensamento de plantas, a desponta das plantas e a condução de uma haste por planta estão relacionadas com a produtividade e a qualidade dos frutos. O aumento da densidade de plantas aumenta a produtividade de frutos (Streck et al., 1998; Seleguini et al., 2006; Machado et al., 2007), porém reduz a massa média de fruto (Streck et al., 1998; Carvalho \& Tessarioli Neto, 2005; Machado et al., 2007). Por outro lado com a desponta é limitado o número de cachos por haste, o que propicia aumento do tamanho dos frutos remanescentes (Machado et al., 2007), principalmente daqueles localizados nos últimos cachos (Pereira et al., 1999). Por fim a condução de uma haste por planta está relacionada ao aumento da produtividade comercial de frutos (Carvalho \& Tessarioli Neto, 2005; Marim et al., 2005; Wamser et al., 2007).

Uma novidade apresentada na proposta de tomateiro superadensado é a abertura das hastes das plantas formando um "V" ao longo das filas de plantio. O aumento da sobreposição e do sombreamento das folhas com o adensamento de plantas diminui a penetração da radiação fotossinteticamente ativa no dossel da cultura e, consequentemente, a taxa fotossintética das plantas diminui (Papadopoulos \& Pararajasingham, 1997). Por outro lado, o adensamento de plantas também pode aumentar a severidade de doenças foliares (Wamser et al., 2008). Espera-se que esta abertura das hastes melhore a penetração da radiação solar, contribuindo no aumento da produção de fotoassimilados destinados à fixação e ao crescimento dos frutos, e aumente a aeração do dossel da cultura, diminuindo as condições favoráveis ao desenvolvimento de doenças.

A magnitude da resposta do tomateiro ao adensamento de plantas pode variar de acordo com o genótipo, como observado por Carvalho \& Tessarioli Neto (2005) e Machado et al. (2007) para a massa média de frutos. Isto está relacionado às diferenças encontradas nos genótipos com relação à arquitetura de plantas, distribuição da produção de frutos ao longo da planta (Oliveira et al., 1995) e suscetibilidade a doenças. Desta forma, torna-se importante a avaliação do adensamento de plantas em genótipos de tomate com diferentes características agronômicas.

A associação da técnica de desponta das plantas, mantendo-se cinco a sete cachos/haste, a condução de uma haste por planta, o tutoramento de plantas com fitilho em "V" e o adensamento do tomateiro, podem promover o aumento na produtividade sem comprometer a qualidade dos frutos e o controle fitossanitário. Por outro lado, os tomaticultores da região de Caçador necessitam de resultados experimentais do cultivo superadensado, com os híbridos cultivados nas condições edafoclimáticas da região, para que possam decidir sobre a adoção deste sistema. Desta forma, o objetivo deste trabalho foi avaliar o cultivo superadensado de tomate com híbridos utilizados em Caçador.

\section{MATERIAL E MÉTODOS}

Dois experimentos foram realizados durante as safras 2007/2008 e 2008/2009 em Caçador. O clima da região é temperado constante úmido, com verão ameno, do tipo $\mathrm{Cfb}$, conforme a classificação de Köppen (Pandolfo et al., 2002). Os dados de temperatura máxima e mínima e precipitação diária durante o ciclo da cultura (Figura 1) foram obtidos na Epagri, Estação Meteorológica de Caçador, localizada a $400 \mathrm{~m}$ das áreas experimentais $\left(26^{\circ} 48^{\prime} 58^{\prime \prime} \mathrm{S}, 50^{\circ} 59^{\prime} 34^{\prime \prime} \mathrm{W}\right)$. A área de 2008/2009 era adjacente a área de 2007/2008. Os solos nos locais dos experimentos foram classificados como Latossolo Bruno distrófico típico (Embrapa, 1999) e apresentaram os seguintes atributos: $\mathrm{pH}$ (água) $=6,1$ e
$5,9, \mathrm{P}=3,6$ e $9,9 \mathrm{mg} \mathrm{dm}^{-3}, \mathrm{~K}=0,27$ e $0,42 \mathrm{mmol}_{\mathrm{c}} \mathrm{dm}^{-3}, \mathrm{MO}=4,2$ e 5,6 $\mathrm{g} \mathrm{dm}^{-3}$, $\mathrm{Al}=0,0$ e $0,0 \mathrm{mmol} \mathrm{dm}^{-3}, \mathrm{Ca}=9,6$ e 8,6 mmol $\mathrm{dm}^{-3}, \mathrm{Mg}=4,1$ e $3,7 \mathrm{mmol}_{\mathrm{c}} \mathrm{dm}^{-3}$, $\mathrm{V} \%=80$ e 72 , para as safras $2007 / 2008$ e 2008/2009, respectivamente.

Os tratamentos na safra 2007/2008 consistiram na combinação de dois híbridos (Miramar e T92), dois métodos de tutoramento de plantas (vertical e em "V") e dois métodos de condução de plantas (uma haste por planta no espaçamento entre plantas de $0,15 \mathrm{~m} \mathrm{e}$ duas hastes por planta no espaçamento entre plantas de $0,3 \mathrm{~m}$ ). Todos os tratamentos possuíam 44.444 hastes/ha. $\mathrm{O}$ delineamento experimental foi de blocos completos ao acaso, com quatro repetições, no esquema de parcelas sub-subdivididas, alocando-se a fator híbrido na parcela, o fator método de tutoramento de plantas na subparcela e o fator método de condução de plantas na sub-subparcela.

Os tratamentos na safra 2008/2009 consistiram na combinação de dois híbridos (Paron e Plutão) e dois métodos de condução de plantas para o tomateiro superadensado (uma haste por planta no espaçamento entre plantas de $0,15 \mathrm{~m} \mathrm{e}$ duas hastes por planta no espaçamento entre plantas de $0,3 \mathrm{~m}$ ), mais o método de condução para a densidade tradicional de plantas (duas hastes por planta no espaçamento entre plantas de 0,6 $\mathrm{m})$. Os tratamentos com espaçamento entre plantas de 0,15 e 0,3 m possuíam 44.444 hastes/ha e foram tutorados em "V". Os tratamentos com espaçamento entre plantas de $0,6 \mathrm{~m}$ possuíam 22.222 hastes/ha, foram tutorados verticalmente e representam a densidade de plantas tradicional da região de Caçador (Figura 2). Nesta safra foram usados híbridos diferentes da safra 2007/2008 com o objetivo de avaliar o método de produção do tomateiro superadensado abrangendo maior número de híbridos utilizados na região de Caçador. O delineamento experimental foi de blocos completos ao acaso, com quatro repetições, no esquema de parcelas subdivididas, alocando-se a fator híbrido na parcela, o fator método de condução de plantas na subparcela.

As unidades experimentais nas duas safras foram constituídas de uma linha 
de plantas com 6,0 $\mathrm{m}$ de comprimento e espaçamento entre linhas de $1,5 \mathrm{~m}$, com área útil de $9,0 \mathrm{~m}^{2}$. No método de produção de tomateiro superadensado tutorado em "V", as hastes das plantas foram conduzidas em fitilhos amarrados de forma alternada em dois arames fixados nos moirões, em altura aproximadamente de $1,8 \mathrm{~m}$ afastados $0,5 \mathrm{~m}$ entre si. No método de produção de tomateiro superadensado tutorado verticalmente, todas as hastes foram conduzidas em fitilhos amarrados em um único arame superior. Os arames superiores foram dispostos ao longo das filas na altura de 1,8 m (Figura 2).

Utilizou-se o sistema de plantio direto sobre a palha de aveia branca, sem aplicação de herbicida para a dessecação desta. A adubação de plantio foi feita no sulco de plantio utilizando $435 \mathrm{~kg} \mathrm{ha}^{-1}$ de $\mathrm{P}_{2} \mathrm{O}_{5}$ (superfosfato triplo), $7 \mathrm{tha}^{-1} \mathrm{de}$ esterco de aves, $2,7 \mathrm{~kg} \mathrm{ha}^{-1}$ de B (bórax) e $8 \mathrm{~kg} \mathrm{ha}^{-1}$ de $\mathrm{Zn}$ (sulfato de zinco) na safra 2007/2008. Na safra 2008/2009 foram aplicados, no plantio, $50 \mathrm{~kg} \mathrm{ha}^{-1}$ de $\mathrm{N}$ (nitrato de amônio), $750 \mathrm{~kg} \mathrm{ha}^{-1} \mathrm{de}$ $\mathrm{P}_{2} \mathrm{O}_{5}$ (superfosfato triplo), $52,5 \mathrm{~kg} \mathrm{ha}^{-1}$ de $\mathrm{K}_{2} \mathrm{O}$ (cloreto de potássio) e $3,0 \mathrm{~kg} \mathrm{ha}^{-1}$ de B (bórax). O plantio foi realizado em $21 / 11 / 2007$ e 28/11/2008. As adubações de cobertura foram realizadas semanalmente, a partir dos 21 dias após o plantio (DAP), totalizando $422 \mathrm{~kg} \mathrm{ha}^{-1}$ de $\mathrm{N}$ (nitrato de amônio) e $405 \mathrm{~kg} \mathrm{ha}^{-1}$ de $\mathrm{K}_{2} \mathrm{O}$ (cloreto de potássio) na safra 2007/2008, e $565 \mathrm{~kg} \mathrm{ha}^{-1}$ de $\mathrm{N}$ e $593 \mathrm{~kg} \mathrm{ha}^{-1}$ de $\mathrm{K}_{2} \mathrm{O}$ (nitrato de amônio e nitrato de potássio) na safra 2008/2009. As plantas foram despontadas mantendo três folhas acima do $6^{\circ}$ e $7^{\circ}$ cacho da haste secundária e principal, respectivamente. As demais práticas culturais foram realizadas de acordo com as Indicações técnicas para o tomateiro tutorado na região do Alto Vale do Rio do Peixe (Mueller et al., 2008).

Avaliou-se a produtividade total, comercial e descarte, e a massa média de frutos comerciais de materiais colhidos na área útil. Os frutos comerciais foram classificados nas classes extra AA (massa maior que $150 \mathrm{~g}$ ) e extra A (massa entre 100 e $150 \mathrm{~g}$ ). Foram considerados como descarte os frutos com doenças fisiológicas ou fitopatológicas, com ataque de insetos-praga e frutos miúdos (massa menor que $100 \mathrm{~g}$ ). As severidades de requeima (Phytophthora infestans), pinta-preta (Alternaria solani) e mancha bacteriana (Xanthomonas campestris pv. $v$ e s icatoria) nas plantas foram avaliadas aos 105 e 112 DAP, nas safras em questão, respectivamente, com auxílio de escalas diagramáticas para requeima (James, 1971), pinta-preta (Boff et al., 1991) e mancha bacteriana (Mello et al., 1997).

Os dados obtidos foram submetidos à análise de variância (teste $\mathrm{F}$ ). Havendo significância estatística $(\mathrm{p} \leq 0,05)$, as médias foram comparadas pelo teste de Tukey a 5\% de probabilidade de erro. Os dados de severidade de doenças foram transformados em $(\mathrm{x}+0,5)^{0,5}$. Para a comparação entre os métodos de condução ou tutoramento do tomateiro avaliados foi calculado a superioridade relativa (SR) através da seguinte equação: $\mathrm{SR}(\%)=[$ (método $\mathrm{A} /$ método B)-1]x100.

\section{RESULTADOS E DISCUSSÃO}

Os dados de temperatura máxima e mínima e precipitação diária se encontram na Figura 1. Na safra 2007/2008 foram registrados 62 dias de chuva com uma precipitação de 403,5 mm durante o ciclo da cultura, enquanto que na safra 2008/2009 foram 66 dias de chuva e uma precipitação de 548,5 $\mathrm{mm}$. Nas duas safras as precipitações foram menores que a média histórica (1961-2008), sendo 626,0 e 697,6 mm para o período das safras 2007/2008 e 2008/2009, respectivamente.

$\mathrm{Na}$ avaliação de doenças houve ocorrência apenas de pinta-preta e mancha-bacteriana. Não houve interação entre os fatores para todas as variáveis avaliadas $(p>0,05)$. Este resultado permite inferir que os híbridos testados não interferem nas respostas agronômicas ao adensamento de plantas. Entretanto, na safra 2007/2008 os híbridos testados se diferiram para a massa média de frutos, e na 2008/2009 se diferiram em termos de produtividade e massa média de frutos (Tabela 1 e 2). A produtividade total, comercial, extra AA e descarte de frutos e a massa média de frutos comercial, extra AA e extra A de frutos foram maiores no híbrido
Paron, em relação ao híbrido Plutão. Tomates do grupo salada, como o Paron, possuem produtividade e massa média de frutos maiores que frutos do grupo saladete, como o Plutão (Epagri, 2006). Já a massa média de frutos comercial, extra AA e extra A foi maior no híbrido T92, em relação ao híbrido Miramar, corroborando com as características produtivas relatadas pelas respectivas empresas de sementes (Seminis, 2011; Takii do Brasil, 2011). Para a severidade de doenças, houve diferença entre híbridos somente para mancha-bacteriana na safra 2007/2008. A maior severidade de mancha-bacteriana ocorreu no híbrido T92, em relação ao híbrido Miramar.

Comparando-se os métodos de tutoramento de plantas para o tomateiro superadensado na safra 2007/2008, o tutoramento em " $\mathrm{V}$ " proporcionou maior produtividade de frutos total $(18,6 \%)$, comercial $(19,2 \%)$, extra AA $(19,8 \%)$ e extra A $(18,6 \%)$, em relação ao tutoramento vertical (Tabela 1). Já a massa média de frutos não foi influenciada pelo método de tutoramento de plantas (Tabela 2), o que evidencia que o aumento da produtividade de frutos no tutoramento em "V" está relacionado ao aumento do número de frutos por planta. Possivelmente, para a densidade de 44.444 hastes/ha, a maior distância entre as hastes proporcionada pelo tutoramento em " $\mathrm{V}$ " aumentou a penetração da radiação solar no dossel da cultura, aumentando assim, a taxa fotossintética total das plantas e a disponibilidade de fotoassimilados para o desenvolvimento dos frutos. A deficiência de fotoassimilados induz a planta a ajustar o número de frutos pelo abortamento de flores (Picanço et al., 1998) e frutos (Sandri et al., 2002).

Os métodos de tutoramento para o tomateiro superadensado não influenciaram a severidade das doenças foliares pinta-preta e mancha bacteriana (Tabela 3 ). Isto pode ser atribuído ao fato de que estas doenças incidem inicialmente no estrato inferior das plantas. Nesta parte a proximidade das hastes no tutoramento em "V" é parecida ao tutoramento vertical, proporcionando condições semelhantes ao aparecimento de doenças.

Não houve diferenças entre os métodos de condução de plantas com 
Tabela 1. Produtividade de frutos total, comercial e descarte em função do híbrido, do método de tutoramento e do método de condução de plantas (total, marketable and unmarketable yield depending on the hybrid, staking methods and plant training methods). Caçador, Epagri, 2007-2009.

\begin{tabular}{|c|c|c|c|c|c|c|c|c|c|c|}
\hline \multirow{3}{*}{ Fatores $^{1}$} & \multicolumn{10}{|c|}{ Produtividade de frutos (t/ha) } \\
\hline & \multicolumn{5}{|c|}{ Safra 2007/2008 } & \multicolumn{5}{|c|}{ Safra 2008/2009 } \\
\hline & Total & Comercial & Extra AA & Extra A & Descarte & Total & Comercial & Extra AA & Extra A & Descarte \\
\hline \multicolumn{11}{|l|}{ Híbrido } \\
\hline Miramar & $170,7 \mathrm{a}$ & $152,5 \mathrm{a}$ & $81,7 \mathrm{a}$ & $70,7 \mathrm{a}$ & $18,3 \mathrm{a}$ & - & - & - & - & - \\
\hline T92 & $158,0 \mathrm{a}$ & $143,7 \mathrm{a}$ & $84,0 \mathrm{a}$ & $59,8 b$ & $14,2 \mathrm{a}$ & - & - & - & - & - \\
\hline Paron & - & - & - & - & - & $128,5 \mathrm{a}$ & $113,9 \mathrm{a}$ & $75,8 \mathrm{a}$ & $38,1 \mathrm{~b}$ & $14,6 \mathrm{a}$ \\
\hline Plutão & - & - & - & - & - & $114,8 b$ & $104,6 b$ & $59,6 \mathrm{~b}$ & $45,0 \mathrm{a}$ & $10,2 b$ \\
\hline \multicolumn{11}{|c|}{ Método de tutoramento } \\
\hline Vertical & $150,4 \mathrm{~b}$ & $135,1 b$ & $75,4 b$ & $59,7 b$ & $15,2 \mathrm{a}$ & - & - & - & - & - \\
\hline "V" & $178,3 \mathrm{a}$ & $161,1 \mathrm{a}$ & $90,3 \mathrm{a}$ & $70,8 \mathrm{a}$ & $17,3 \mathrm{a}$ & - & - & - & - & - \\
\hline \multicolumn{11}{|c|}{ Método de condução - número de hastes por planta (espaçamento entre plantas) } \\
\hline Uma $(15 \mathrm{~cm})$ & $167,1 \mathrm{a}$ & $150,3 \mathrm{a}$ & $81,5 \mathrm{a}$ & $68,8 \mathrm{a}$ & $16,9 \mathrm{a}$ & $148,8 \mathrm{a}$ & $133,4 \mathrm{a}$ & $80,0 \mathrm{a}$ & $53,4 \mathrm{a}$ & $15,4 \mathrm{a}$ \\
\hline Duas $(30 \mathrm{~cm})$ & $161,6 \mathrm{a}$ & $145,9 \mathrm{a}$ & $84,2 \mathrm{a}$ & $61,7 b$ & $15,7 \mathrm{a}$ & $134,8 b$ & $120,8 b$ & $74,1 \mathrm{a}$ & $46,7 \mathrm{~b}$ & $14,0 \mathrm{a}$ \\
\hline Duas $(60 \mathrm{~cm})$ & - & - & - & - & - & $81,3 \mathrm{c}$ & $73,4 \mathrm{c}$ & $49,0 \mathrm{~b}$ & $24,4 \mathrm{c}$ & $7,9 \mathrm{~b}$ \\
\hline Média & 164,3 & 148,1 & 82,8 & 65,3 & 16,2 & 121,7 & 109,2 & 67,7 & 41,5 & 12,5 \\
\hline$\overline{\mathrm{CV}} 1(\%)$ & 10,7 & 12,4 & 18,7 & 8,4 & 22,6 & 6,6 & 6,2 & 20,9 & 6,7 & 8,4 \\
\hline CV $2(\%)$ & 3,1 & 4,9 & 13,8 & 8,7 & 37,3 & 5,7 & 6,0 & 10,3 & 7,6 & 13,2 \\
\hline CV $3(\%)$ & 5,9 & 9,6 & 14,4 & 7,3 & 18,1 & - & - & - & - & - \\
\hline
\end{tabular}

${ }^{1}$ Médias seguidas pela mesma letra na coluna em cada variável analisada, dentro de cada fator, não diferem entre si pelo teste de Tukey $(\alpha=0,05)$. CV 1, CV 2 e CV 3 = coeficientes de variação para parcelas, subparcelas e sub-subparcelas, respectivamente ( ${ }^{1}$ means followed by same letter in each evaluated variable, in each tested factor, did not differ through the Tukey test $(\alpha=0.05)$. CV $1, \mathrm{CV} 2$ and CV $3=$ coefficients of variation for plots, subplots and sub-subplots, respectively).

Tabela 2. Massa média de frutos comerciais em função do híbrido, do método de tutoramento e do método de condução de plantas (marketable fruit average weight depending on the hybrid, staking method and plant training method). Caçador, Epagri, 2007-2009.

\begin{tabular}{|c|c|c|c|c|c|c|}
\hline \multirow{3}{*}{ Fatores $^{1}$} & \multicolumn{6}{|c|}{ Massa média de fruto (g) } \\
\hline & \multicolumn{3}{|c|}{ Safra $2007 / 2008$} & \multicolumn{3}{|c|}{ Safra 2008/2009 } \\
\hline & Comercial & Extra AA & Extra A & Comercial & Extra AA & Extra A \\
\hline \multicolumn{7}{|l|}{ Híbrido } \\
\hline Miramar & $150,4 \mathrm{~b}$ & $177,9 b$ & $127,7 \mathrm{~b}$ & - & - & - \\
\hline T92 & $156,7 \mathrm{a}$ & $182,4 \mathrm{a}$ & $130,7 \mathrm{a}$ & - & - & - \\
\hline Paron & - & - & - & $160,4 a$ & $179,9 \mathrm{a}$ & $130,9 \mathrm{a}$ \\
\hline Plutão & - & - & - & $141,3 b$ & $160,0 \mathrm{~b}$ & $121,8 \mathrm{~b}$ \\
\hline \multicolumn{7}{|c|}{ Método de tutoramento } \\
\hline Vertical & $153,2 \mathrm{a}$ & $179,6 a$ & $129,2 \mathrm{a}$ & - & - & - \\
\hline "V" & $153,8 \mathrm{a}$ & $180,6 \mathrm{a}$ & $129,2 \mathrm{a}$ & - & - & - \\
\hline \multicolumn{7}{|c|}{ Método de condução - número de hastes por planta (espaçamento entre plantas) } \\
\hline Uma $(15 \mathrm{~cm})$ & $151,4 \mathrm{a}$ & $178,6 \mathrm{a}$ & $128,1 \mathrm{~b}$ & $146,0 \mathrm{c}$ & $164,1 \mathrm{c}$ & $125,2 \mathrm{~b}$ \\
\hline Duas $(30 \mathrm{~cm})$ & $155,6 \mathrm{a}$ & $181,6 \mathrm{a}$ & $130,3 \mathrm{a}$ & $150,1 b$ & $169,5 b$ & $126,4 \mathrm{ab}$ \\
\hline Duas $(60 \mathrm{~cm})$ & - & - & - & $156,6 \mathrm{a}$ & $176,2 \mathrm{a}$ & $127,4 \mathrm{a}$ \\
\hline Média & 153,5 & 180,0 & 129,2 & 150,9 & 169,9 & 126,3 \\
\hline CV $1(\%)$ & 2,4 & 1,4 & 0,6 & 8,9 & 14,0 & 0,7 \\
\hline CV $2(\%)$ & 3,7 & 1,2 & 2,4 & 1,9 & 1,6 & 1,2 \\
\hline CV $3(\%)$ & 2,9 & 2,1 & 1,3 & - & - & - \\
\hline
\end{tabular}

${ }^{1}$ Médias seguidas pela mesma letra na coluna, dentro de cada fator, não diferem entre si pelo teste de Tukey $(\alpha=0,05)$. CV 1, CV 2 e CV 3 = coeficientes de variação para parcelas, subparcelas e sub-subparcelas, respectivamente ( ${ }^{1}$ means followed by the same letter in each evaluated variable, in each tested factor, did not differ through the Tukey test $(\alpha=0.05)$. CV 1 , CV 2 and CV $3=$ coefficients of variation for plots, subplots and sub-subplots, respectively). 

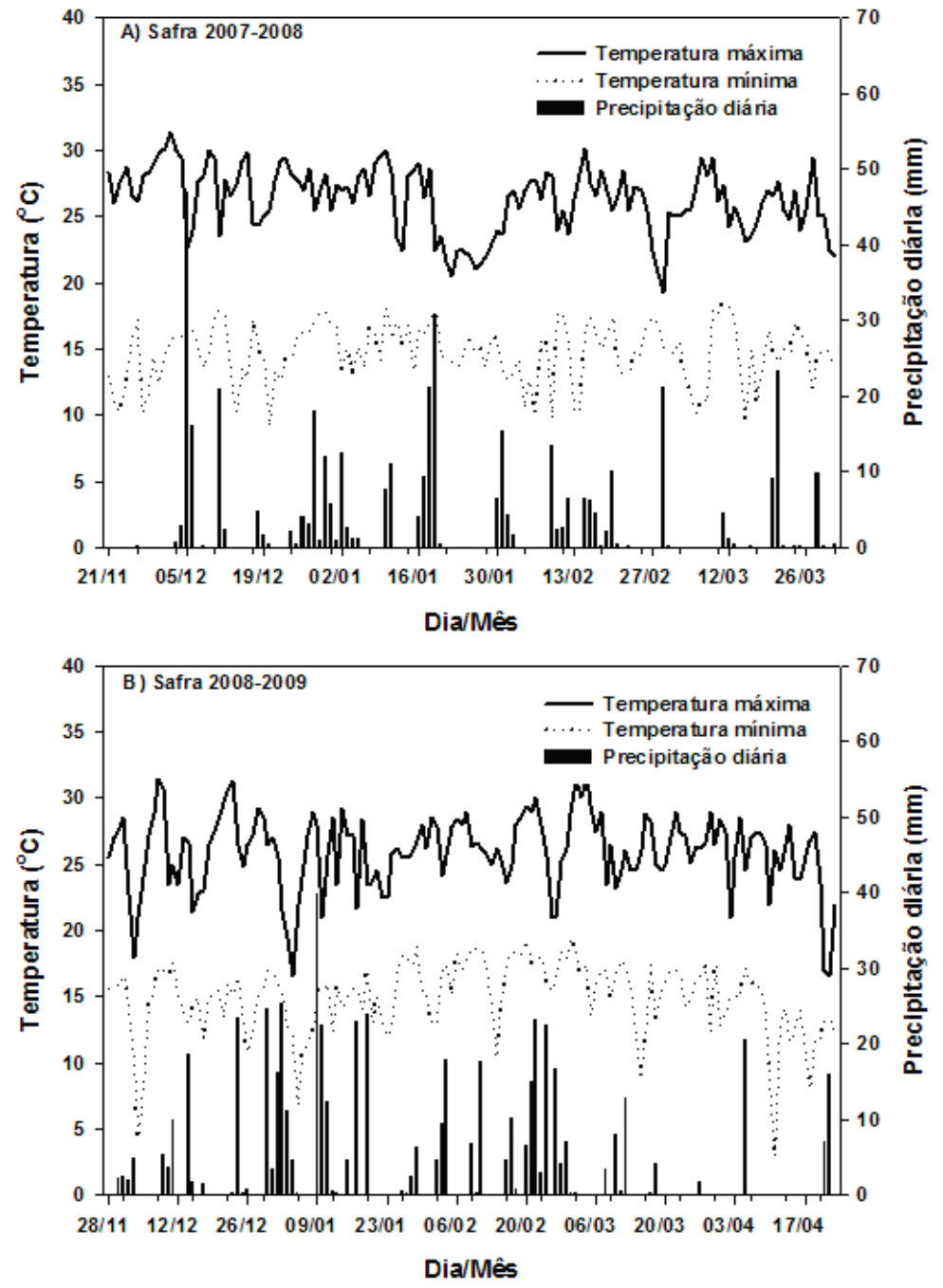

Figura 1. Temperaturas máximas e mínimas e precipitação diária durante o ciclo do tomate nas safras 2007/2008 (A) e 2008/2009 (B) (maximum and minimum temperatures and rainfall during the cycle of tomato crops in 2007/2008 (A) and 2008/2009 (B)). Caçador, Epagri, 2007-2009.

uma e duas hastes por planta na safra $2007 / 2008$ para a produtividade de frutos total, comercial, extra AA e descarte e o mesmo se repetiu para a produtividade de frutos extra AA e descarte na safra 2008/2009 (Tabela 1). Entretanto, na safra 2007/2008 a condução de uma haste por planta no espaçamento de $0,15 \mathrm{~m}$ aumentou a produtividade de frutos extra $\mathrm{A}$ em 11,5\% em relação à condução de duas hastes por planta no espaçamento de $0,3 \mathrm{~m}$ entre plantas. Na safra 2008/2009, a produtividade de frutos total, comercial e extra A foram respectivamente $10,4,10,4$ e $14,3 \%$ maiores na condução com uma haste por planta em relação à condução de duas hastes por planta. Estes resultados estão de acordo com Wamser et al. (2007) que observaram o aumento da produtividade de frutos total e comercial com a condução de uma haste por planta, em relação à condução de duas hastes por planta na densidade de 22.222 hastes/ ha. $\mathrm{O}$ aumento da produtividade com a condução de uma haste por planta está relacionado ao maior número de cachos por área, visto que na condução de duas hastes por planta, a altura de inserção do primeiro cacho da haste secundária fica localizada acima do segundo cacho da haste principal, corroborando aos relatos de Oliveira et al. (1995). A massa média de frutos extra A, na safra 2007/2008, e a massa média de frutos comercial e extra AA, na safra 2008/2009, foram maiores na condução de duas hastes por planta em relação à condução de uma haste por planta (Tabela 2).

Comparando-se o sistema de condução do tomateiro superadensado com a densidade tradicional de plantas na safra 2008/2009, a produtividade de frutos total, comercial, extra AA, extra A e descarte foram maiores no tomateiro superadensado, em média, 74,4, 73,2, $57,2,105,1$ e $86,1 \%$, respectivamente (Tabela 1). As massas médias de frutos comercial e extra AA diminuíram no tomateiro superadensado, tanto com uma ou duas hastes por planta, em relação à densidade tradicional de plantas (Tabela 2). Para a massa média de fruto extra A, somente o tomateiro superadensado conduzido com uma haste por planta diminui a massa média de fruto, em relação à densidade tradicional. Estes resultados estão de acordo com Mueller \& Wamser (2009) que observaram aumento linear na produtividade de frutos comercial e diminuição quadrática da massa média de fruto comercial com o aumento da densidade de 27.000 para 67.000 hastes/ha.

Para a severidade de doenças foliares, não houve diferenças para o tomateiro superadensado com uma haste e duas hastes por plantas nas duas safras (Tabela 3). Estes resultados são diferentes dos encontrados por Wamser et al. (2008) os quais observaram maior severidade de mancha-bacteriana com a condução de uma haste por planta. Entretanto, na safra 2008/2009, a severidade de pinta-preta foi maior no tomateiro superadensado conduzido com duas hastes por planta no espaçamento de $0,30 \mathrm{~m}$ em relação à densidade normal de plantas, não diferindo, contudo, do tomateiro superadensado conduzido com uma haste por planta. Esta maior severidade de pinta-preta, mesmo com a abertura das hastes das plantas pelo tutoramento em " $\mathrm{V}$ " para melhorar a ventilação ao longo do dossel da cultura, possivelmente se deve ao fato de que estes benefícios só ocorrem nos estratos superiores da planta, onde as hastes estão mais afastadas. No estrato inferior, devido à maior proximidade das hastes 


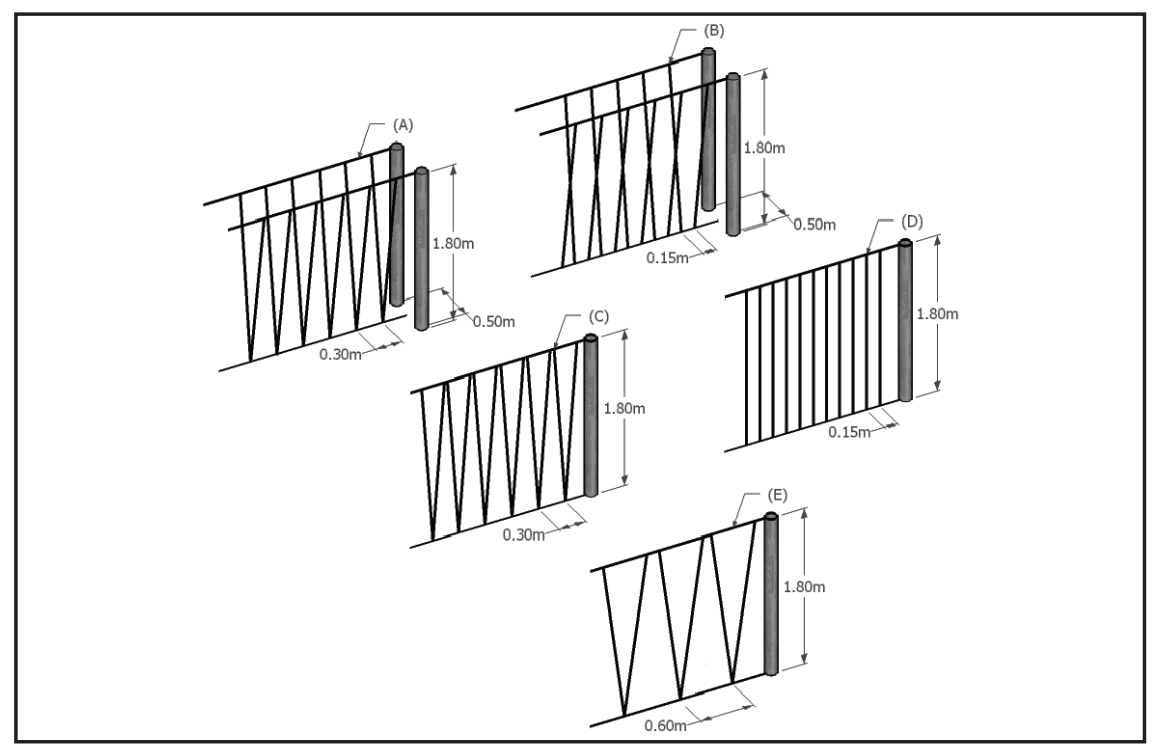

Figura 2. Esquema ilustrativo dos seguintes sistemas de adensamento de plantas: densidade de 44.444 hastes/ha tutorado em "V", conduzindo duas hastes por planta no espaçamento de $0,3 \mathrm{~m}$ entre plantas (A) e uma haste por planta no espaçamento de $0,15 \mathrm{~m}$ entre plantas (B); densidade de 44.444 hastes/ha tutorado verticalmente, conduzindo duas hastes por planta no espaçamento de $0,3 \mathrm{~m}$ entre plantas $(\mathrm{C})$ e uma haste por planta no espaçamento de $0,15 \mathrm{~m}$ entre plantas (D); densidade tradicional de 22.222 hastes/ha tutorado verticalmente, conduzindo duas hastes por planta no espaçamento de $0,6 \mathrm{~m}$ entre plantas (E) (schematic illustration of the following plant density systems: density of 44,444 stems/ha in "V" staking, training two stems per plant in the plant spacing of $0.3 \mathrm{~m}(\mathrm{~A})$ and one stem per plant in the plant spacing of $0.15 \mathrm{~m}(\mathrm{~B})$; density of 44,444 stems/ha in vertical staking, training two stems per plant in the plant spacing of $0.3 \mathrm{~m}(\mathrm{C})$ and one stem per plant in the plant spacing of $0.15 \mathrm{~m}(\mathrm{D})$; traditional density of 22,222 stems/ha in vertical staking, training two stems per plant in the plant spacing of $0.6 \mathrm{~m}(\mathrm{E}))$. Caçador, Epagri, 2007-2009.

Tabela 3. Severidade de doenças foliares em função do híbrido, do método de tutoramento e do método de condução de plantas (severity of leaf diseases depending on the hybrid, staking methods and plant training method). Caçador, Epagri, 2007-2009.

\begin{tabular}{|c|c|c|c|c|}
\hline \multirow{3}{*}{ Fatores $^{1}$} & \multicolumn{4}{|c|}{ Severidade de doenças foliares $(\%)^{2}$} \\
\hline & \multicolumn{2}{|c|}{ Safra $2007 / 2008$} & \multicolumn{2}{|c|}{ Safra 2008/2009 } \\
\hline & $\begin{array}{l}\text { Pinta } \\
\text { preta }\end{array}$ & $\begin{array}{c}\text { Mancha } \\
\text { bacteriana }\end{array}$ & $\begin{array}{l}\text { Pinta } \\
\text { preta }\end{array}$ & $\begin{array}{c}\text { Mancha } \\
\text { bacteriana }\end{array}$ \\
\hline \multicolumn{5}{|l|}{ Híbrido } \\
\hline Miramar & $0,2 \mathrm{a}$ & $3,9 b$ & - & - \\
\hline T92 & $0,2 \mathrm{a}$ & $12,8 \mathrm{a}$ & - & - \\
\hline Paron & - & - & $1,4 \mathrm{a}$ & $0,1 \mathrm{a}$ \\
\hline Plutão & - & - & $0,8 \mathrm{a}$ & $0,3 \mathrm{a}$ \\
\hline \multicolumn{5}{|c|}{ Método de tutoramento } \\
\hline Vertical & $0,3 \mathrm{a}$ & $8,7 \mathrm{a}$ & - & - \\
\hline "V" & $0,1 \mathrm{a}$ & $7,9 \mathrm{a}$ & - & - \\
\hline \multicolumn{5}{|c|}{ Método de condução - número de hastes por planta (espaçamento entre plantas) } \\
\hline Uma $(15 \mathrm{~cm})$ & $0,1 \mathrm{a}$ & $8,5 \mathrm{a}$ & $1,1 \mathrm{ab}$ & $0,1 \mathrm{a}$ \\
\hline Duas $(30 \mathrm{~cm})$ & $0,3 \mathrm{a}$ & $8,2 \mathrm{a}$ & $1,7 \mathrm{a}$ & $0,2 \mathrm{a}$ \\
\hline Duas $(60 \mathrm{~cm})$ & - & - & $0,7 \mathrm{~b}$ & $0,4 \mathrm{a}$ \\
\hline Média & 0,2 & 8,3 & 1,1 & 0,3 \\
\hline CV $1(\%)$ & 8,8 & 16,4 & 30,9 & 2,8 \\
\hline CV $2(\%)$ & 17,6 & 26,5 & 22,8 & 32,0 \\
\hline CV $3(\%)$ & 23,0 & 24,6 & - & - \\
\hline
\end{tabular}

${ }^{1}$ Médias seguidas pela mesma letra na coluna, dentro de cada fator testado, não diferem entre si pelo teste de Tukey $(\alpha=0,05)$; ${ }^{2}$ Dados originais; para análise estatística foram transformados em $y=(x+0,5)^{0,5}\left({ }^{1}\right.$ means followed by the same letter in each evaluated variable, in each tested factor, did not differ through the Tukey test $(\alpha=0.05){ }^{2}$ original data, for statistical analysis data were transformed into $\left.\mathrm{y}=(\mathrm{x}+0.5)^{0.5}\right)$.
(Figura 2), ainda há o favorecimento da disseminação da pinta-preta, principalmente pelo fato de que esta se inicia nas folhas baixeiras da planta. Para a mancha-bacteriana não houve diferença entre o tomateiro superadensado e a densidade tradicional de plantas. Este resultado pode ser atribuído ao eficiente manejo deste fitopatógeno, o que pode ser observado pelo baixo nível de severidade da doença (média de 0,3\% numa escala de severidade que vai de 0 a $100 \%)$.

De acordo com os resultados, as características produtivas e severidade de doenças dos métodos de superadensamento do tomateiro não são influenciadas pelos híbridos testados. Em plantio a campo do tomateiro utilizando a densidade de 44.444 hastes/ha, o tutoramento em "V" aumenta a produtividade comercial de frutos, em relação ao tutoramento vertical de plantas. $\mathrm{O}$ tomateiro superadensado tutorado em " $\mathrm{V}$ " aumenta a produtividade comercial de frutos em relação à densidade tradicional (22.222 hastes/ha). Para o tomateiro superadensado tutorado em "V" a condução de uma haste por planta aumenta a produtividade comercial de frutos em relação à condução de duas hastes por planta. O tomateiro superadensado proporciona aumento da severidade foliar de pinta-preta, em relação à densidade tradicional de plantas.

\section{AGRADECIMENTOS}

Os autores agradecem ao MAPA-CNPq, pelo financiamento dos experimentos, e às empresas Seminis e Sementes Takii, pelo apoio na implantação dos experimentos.

\section{REFERENCIAS}

BOFF P; ZAMBOLIM L; RIBEIRO DO VALE FX. 1991. Escalas para avaliação de severidade da mancha-de-estenfílio (Stemphylium solani) e da pinta-preta (Alternaria solani) em tomateiro. Fitopatologia Brasileira 16: 280-283.

CARVALHO LA; TESSARIOLI NETO J. 2005. Produtividade de tomate em ambiente protegido, em função do espaçamento e número de ramos por planta. Horticultura Brasileira 23: 986-989.

EMBRAPA. 1999. Centro Nacional de Pesquisas 
de Solos. Sistema brasileiro de classificação de solos. Brasília: EMBRAPA. 412p.

EPAGRI. 2006. Avaliação de cultivares para o Estado de Santa Catarina 2006/2007. Florianópolis: EPAGRI. 162p. (Boletim Técnico, 128).

JAMES WC. 1971. An illustrated series of assessment keys for plant diseases, their preparations and usages. Canadian Plant Disease Survey 51: 39-65.

MACHADO AQ; ALVARENGA MAR.; FLORENTINO CET. 2007. Produção de tomate italiano (saladete) sob diferentes densidades de plantio e sistemas de poda visando ao consumo in natura. Horticultura Brasileira 25: 149-153.

MARIM BG; SILVA DJH; GUIMARÃES MA; BELFORT G. 2005. Sistemas de tutoramento e condução do tomateiro visando produção de frutos para consumo in natura. Horticultura Brasileira 23: 951-955.

MELLO SC; TAKATSU A; LOPES CA. 1997. Escala diagramática para avaliação da manchabacteriana do tomateiro. Fitopatologia Brasileira 22: 447-448.

MELO B. 2007. Nova técnica produz mais tomate. O Estado de S. Paulo, 18 abr. 2007. Caderno Agrícola, p.9.

MUELLER S; WAMSER AF. 2009. Combinação da altura de desponte e do espaçamento entre plantas de tomate. Horticultura Brasileira 27: 64-69.
MUELLER S; WAMSER AF; BECKER WF; SANTOS JP. 2008. Indicações técnicas para o tomateiro tutorado na região do Alto Vale do Rio do Peixe. Florianópolis: Epagri. 78p. (Sistemas de Produção, 45).

OLIVEIRA MLC. 2006. Produção de tomate superadensado. Revista Campo \& Negócios $H F$, dez. 2006. Disponível em http:// www.revistacampoenegocios.com.br/ anteriores/12-06/index.php.

OLIVEIRA VR; OLIVEIRA JÚNIOR RS; MELO VF; PELÚZIO JM; FONTES PCR. 1995. Distribuição da produção de frutos nos cachos de cinco cultivares de tomateiro (Lycopersicon esculentum, Mill.) em dois sistemas de condução. Revista Ceres 42: 644-657.

PANDOLFO C; BRAGA HJ; SILVA JÚNIOR VP; MASSIGNAM AM; PEREIRA ES; THOMÉ VMR. 2002. Atlas climáticos digital do Estado de Santa Catarina. Florianópolis: EPAGRI. (CD-ROM).

PAPADOPOULOS AP; PARARAJASINGHAM S. 1997. The influence of plant spacing on light interception and use in greenhouse tomato (Lycopersicon esculentum Mill.): a review. Scientia Horticulturae 69: 1-29.

PEREIRA C; MARCHI G; SILVA EC. 1999. Produção de tomate-caqui em estufa. Lavras: UFLA. 26p. (Boletim técnico. Série extensão).

PICANÇO M; LEITE GLD; GUEDES RNC; SILVA EA. 1998. Yield loss in trellised tomato affected by insecticidal sprays and plant spacing. Crop Protection 17: 447-452.

SANDRI MA; ANDRIOLO JL; WITTER M; DAL ROSS T. 2002. High density of defoliated tomato plants in protected cultivation and its effects on development of trusses and fruits. Horticultura Brasileira 20: 485-489.

SELEGUINI A; SENO S; FARIA JÚNIOR MJA. 2006. Espaçamento entre plantas e número de racimos para tomateiro em ambiente protegido. Acta Scientiarum Agronomy 28: 359-363.

SEMINIS. 2011. Produtos: Tomate indeterminado Miramar. Disponível em http://www.seminis. com.br/products/tomate/miramar.asp. Acessado em 6 de fevereiro de 2011.

STRECK NA; BURIOL GA; ANDRIOLO JL; SANDRI MA. 1998. Influência da densidade de plantas e poda apical drástica na produtividade do tomateiro em estufa de plástico. Pesquisa Agropecuária Brasileira 33: 1105-1112.

TAKII DO BRASIL. 2011. Catálogo eletrônico de produtos: Tomate Takii 92. Disponível em http://www.takii.com.br/tomatet92.html. Acessado em 6 de fevereiro de 2011.

WAMSER AF; BECKER WF; SANTOS JP; MUELLER S. 2008. Influência do sistema de condução do tomateiro sobre a incidência de doenças e insetos-praga. Horticultura Brasileira 26: 180-185.

WAMSER AF; MUELLER S; BECKER WF; SANTOS JP. 2007. Produção do tomateiro em função dos sistemas de condução de plantas. Horticultura Brasileira 25: 238-243. 